\title{
Arthropod Biodiversity in Agricultural, Horticultural and Silvicultural Ecosystems with Special Reference to Spiders (Araneae) in Mid-hills of Meghalaya, India
}

Jyotim Gogoi ( $\sim$ jyotimgogoi@gmail.com )

Central Agricultural University

Kennedy Ningthoujam

Central Agricultural University

\section{Research Article}

Keywords: Biodiversity, Arthropods, Arachnida, Alpha and Beta Diversity

Posted Date: July 2nd, 2021

DOl: https://doi.org/10.21203/rs.3.rs-640064/v1

License: (c) (1) This work is licensed under a Creative Commons Attribution 4.0 International License.

Read Full License 
Arthropod Biodiversity in Agricultural, Horticultural and Silvicultural Ecosystems with Special

\title{
Reference to Spiders (Araneae) in Mid-hills of Meghalaya, India
}

Gogoi, J. ${ }^{1}$ and Ningthoujam, K. ${ }^{2}$

1 School of Crop Protection

College of Post-Graduate Studies in Agricultural Sciences

Central Agricultural University, Meghalaya-793103

2 Assistant Professor (Entomology)

School of Crop Protection

College of Post-Graduate Studies in Agricultural Sciences

Central Agricultural University, Meghalaya-793103

\begin{abstract}
Spiders are the Arthropod and belong to the Phylum: Arthropoda, Class: Arachnida, Order: Araneae. Their occurrence worldwide is about 30,000 species belonging to the 60 families. Totally 4023 arthropods were collected from Silvicultural, Horticultural and Agricultural ecosystem (Maize, Potato and Rice) which belonged to 14 orders and 85 Nos. of different families. Among the ecosystem maximum diversity found in Silvicultural followed by Horticultural and Agricultural ecosystem in terms of alpha diversity such as Shannon Wiener index Simpsons D, Species number, Margelef D, Equitability J, Berger Parker index, Maclntosch U, Brillouin level, Fisher Alpha, Q Statistic and beta diversity such as Whittaker Bw, Cody Bc, Routledge Br, Routledge Bi, Routledge Be and Wilson \& Shmida Bt.
\end{abstract}

Key words: Biodiversity, Arthropods, Arachnida, Alpha and Beta Diversity 


\section{Introduction}

Biological diversity is the first terminology used by biologist Lovejoy in the year 1890 to describe numbers of species. E. O. Wilson first used the term 'Biodiversity' in written form in the proceedings of U.S. Strategy Conference on Biological Diversity (1981) held on Washington D.C. (Swingland, 2001). Biodiversity can be measured in terms of genetic diversity and the identity and number of different types of species, assemblages of species, biotic communities, and biotic processes, and the amount (e.g., abundance, biomass, cover, rate) and structure of each. It can be observed and measured at any spatial scale ranging from microsites and habitat patches to the entire biosphere" (DeLong, 1996). Spiders utilize a wide range of strategies for capturing preys which makes them a 'model predator' by trapping the prey in sticky webs, lassoing with sticky balls, mimicking the prey to avoid detection and they mainly detect the prey by sensing vibrations, but in case of active hunters they possess acute vision. In natural habitat spiders also have many predators therefore they possess some defence mechanism to defend themselves; ability to blend with the environment as a form of camouflage, flick hairs at their enemies, webs which will trap the predators as well as prey and the venom which is the most powerful defence mechanism. In terrestrial ecosystem, they constitute the most abundant predator and consume large number of preys without damaging the plant, only feeding on insects, their larvae and eggs. In Tapioca plantation maximum diversity was found in predatory spider family Argiopidae (32.5\%) followed by Aranidae (26.2\%), Tetragnathidae, Lycosidae and Lynyphiidae. The most abundant spider was Neoscona theisi in the field due to plant architecture of tapioca plants. Large orb web weaver (Araneidae and Argiopidae) trapped large prey species of Orthopteran insects Hieroglypus feanian and Lepidoptera insects Scirphaga incertulas and Malanitis leda ismena, while Tetrangnatha maxillosa trapped small soft-bodied Dipteran insects Orseolia oryzae (74.6\%) and Hemipteran insects Nephotettix virescens (25.4\%). The cone web spiders capture N. virescens $(60.7 \%)$ and other Orthopteran (39.3\%) insect (Sankari and Thiyagesan, 2010). The denominated spider group in orchard ecosystems areclubionid spiders (Clubiona pallidula, Clubiona phragmitis and Cheiracanthium mildei). Stripped lynx spider (Oxyopes salticus), green lynx spider (Peucetia viridans) and jumping spider (Phidippus audax) are the predatory spiders reported in cotton ecosystems which limits the pest flea hopper (Pseudatomoscellis seriatus), tarnished plant bug (Lygus lineolaris) and noctuids (Heliothis spp.). Clubionid species Cheiracanthium mildei and Cucurbitina opistographa are the predatory spider dominated in apple orchards and limits apple leaf miner (Phyllonorycter blancardella), Psylla mali, Anthonomus pomorum and apple mite (Bogya, 1999). Overall objective of research work is to enhance the scientific understanding of the silvicultural, horticultural and agricultural arthropod, with special reference on spider community, as a basis for an improved, conservation oriented management practices. Conservation of biodiversity without knowing its component is meaningless. In order to understand how to sustain biodiversity, we should be concerned about arthropods. The objectives of the study are:

1.1 Collection and identification of various arthropod fauna in agricultural, horticultural and silvicultural ecosystems.

1.2 To find out arthropod diversity, richness and abundance in agricultural, horticultural and silvicultural ecosystems.

\section{Materials and methods}

The investigation was carried out at Experimental farm of CPGSAS, CAU, Umiam during the time period 02 July, 2019 to 11 February, 2020. Weekly observation were taken from 1st standard meteorological week (SMW) i.e. 
$27^{\text {th }}$ SMW of July, 2018 onwards till $06^{\text {th }}$ SMW of February, 2019. The sample collection was done in 3 ecosystems and took an area about $(10 \times 10) \mathrm{m}^{2}, 100 \mathrm{~m}^{2}$ Viz., Agricultural ecosystems (Maize, Zea mays L.; Potato, Solanum tuberosum L. and Rice, Oryza sativa L.), Horticultural (Citrus, Citrus limon L. and Turmeric, Curcuma longa L.) ecosystem and Silvicultural (Native forest dominated by Pine, Pinus insularis Endl. trees) ecosystem.

\subsubsection{Sampling methods}

Collection of arthropods was done through hand picking, using aspirators, sweep nets, Inverted umbrella, pitfall trap and rubbish trap. Both adults and larval/nymphal forms were collected and immature stages of the insects will be reared for emergence of adult for easier and proper identification. For carrying out arthropods collection, the plot was divided into 100 quadrats measuring $10 \mathrm{~m} \times 10 \mathrm{~m}$. Five such quadrats were chosen each at four corners and one in the middle. In each of the quadrats five pitfall traps were installed and the entire plot was covered during the sampling period.

\subsubsection{Collection techniques}

The collection of arthropod samples was done by standard protocol such as net sweeping, pitfall trapping, ground and aerial hand collection etc. which was used by Schuldt et al. (2008) and Kujur and Ekka (2016). Spiders and insects from rocks, logs, debris and bark of the trees were collected by hand picking and active searching. This method was used by Rajendran et al. (2017) for the collection of arachnids from orange orchards. For collection of ground dwelling arthropods pitfall traps were used which is buried in soil and filled with $4 \%$ formaldehyde solution or teepol for reduced surface tension and fixative and a total of 5-6 traps were placed $1 \mathrm{~m}$ apart in an area of $100 \mathrm{~m}^{2}$ Which was used by Bouseksou et al. (2015), Khan and Rather (2012) and Kujur and Ekka (2016).

\subsubsection{Preservation of Arthropods}

Spiders and insects were killed using chloroform and the specimens were preserved in $5 \mathrm{ml}$ glass vials with 70 per cent ethyl alcohol (70 parts of 100 per cent alcohol +30 parts of distilled water) which was used by Joseph and Premila (2016). Khan (2009) and Khan and Rather (2012) also followed the standard protocol for preserving the very small spider specimens and the juvenile spiders in Oudeman's fluid ( 85 parts of 70 per cent alcohol +5 parts of glycerine +8 parts of glacial acetic acid +2 parts distilled water), the same protocol was followed for preservation of spiderlings.

\subsubsection{Identification of Arthropods}

The most common and important arthropod species were identified to the lowest possible taxon. Identification was done based on established taxonomic keys and literature (Tikader and Bal, 1980; Tikader, 1987; Barrian and Litsinger, 1995; Plantinck, 2011; Khan and Khan, 2011). Cataloguing and documentation was done using images and photographs. Spiders were identified by Dr. Manju Siliwal, Arachnologist at Wildlife Institute of India, Dehradun.

\subsection{Measure of biodiversity indices}

\subsubsection{Alpha Diversity indices}

Measures of diversity are frequently seen as indicators of the wellbeing of any ecosystem. They also serve as a measure of the species diversity in the ecosystem. The following indices were worked out basis of month wise to assess the diversity and distribution of arthropods in observed ecosystems. Species richness indices, Margalef's D, 
(Clifford and Stephenson, 1975), Fisher's alpha (Fisher et al., 1943), Shannon diversity index (Batten, 1976), Brillouin diversity index (Magurran, 1987), Q statistic (Kempton and Taylor, 1976), Species dominance indices, McIntosh index (McIntosh, 1967), Simpson's index (Simpson, 1949), Berger-parker diversity index (Berger and parker, 1970) and Evenness indices.

\subsubsection{Beta diversity indices}

Beta diversity measures measures two attributes, the number of distinct habitats within a region and the replacement of species by another between disjoint parts of the same habitat. All of the selected samples in the active data set will be used to calculate the indices. It is assumed that the samples are arranged in the data grid in their order of occurrence along the transect. The six indices calculated, which are described below are those considered by Wilson and Schmida (1984). All six required presence or absence of data. Following indices were evaluated Whittaker's measure $(\beta \mathrm{w})$, Coby Bc and Routledge's R, I \& E.

\section{Results}

\subsubsection{Arthropods}

The collected samples belonged to 2 classes of arthropods Viz., Arachnida and hexapoda (Insecta). The experiment focuses especially on Arachnida and the diversity of class Arachnida is given in the Table 1 to 12 . Totally 4023 arthropods were collected from silvicultural, horticultural and agricultural ecosystem which belonged to 14 orders and 85 Nos. of different families (Table 1). In familial level maximum diversity was found in class Insecta composed of 66 Nos. of family and 186 Nos. of genera and class Arachnida composed of 19 Nos. of family and 67 Nos. of genera (Table 2). In ordinal level maximum diversity was found in class Insecta composed of 13 Nos. of family and class Arachnida composed of 1 Nos. of family.

\subsubsection{Arachnida}

Under class Arachnida, araneae were the most unique groups. Under Araneae most individuals belonged to the family Araneidae (1456) followed by Tetragnathidae (432), Lycosidae (392), Salticidae (345), Ganophosidae (190), Theridiidae (120), Oxyopidae (111), Linyphiidae (82), Zodariidae (47), Thomisidae (35), Corinnidae (19), Clubionidae (17), Cheiracanthiidae (11), Sparassidae (9), Mimetidae (8), Pisauridae (8), Philodromidae (6) and Pholcidae (1) (Fig. 1.15). Majority of individuals under family Araneidae were of the genus Cyclosa, Argiope and Neoscona while under family Lycosidae, Tetragnathidae, Salticidae and Gnaphosidae the genus Pardosa, Mesida, Plexippus and Haplodrassus were the most abundant genus found respectively. On the other hand for individual ecosystem maximum diversity were found in silvicultural ecosystem (18 Nos. family) followed by horticultural (13 Nos. family), rice (11 Nos. family), maize (4 Nos. family) and potato (4 Nos. family) ecosystem (Fig. 1). In species level maximum diversity found in Neoscona (Aranidae) followed by Cyclosa (Aranidae), Argiope (Aranidae), Pardosa (Lycosidae) (Table 3).

At silvicultural ecosystems a total of 1001 Nos. individuals of Archinids were collected which composed with 18 numbers of families under 59 Nos. of genus and 99 Nos. of species. Maximum species was collected at the month of July to august. The maximum diversity of araneofauna found in generic level in family Araneidae (13) followed by Salticidae (9), Tetragnathidae (7), Ganophosidae (5), Theridiidae (4), Lycosidae (4), Zodariidae (3), Sparassidae (2), Thomisidae (2), Philodromidae (1), Pholcidae (1), Linyphiidae (1), Oxyopidae (1), Mimetidae (1), Clubionidae(1), Corinnidae (1), Cheiracanthiidae (1) and Pisauridae (1) (Plate $1.1 \& 1.2$ ). The maximum individuals was found in the family Araneidae (418) followed by Lycosidae (140), Salticidae (129), Tetragnathidae (117), 
Ganophosidae (60), Theridiidae (55), Linyphiidae (18), Zodariidae (12), Oxyopidae (11), Sparassidae (9), Pisauridae (8), Corinnidae (7), Thomisidae (7), Philodromidae (6), Clubionidae(3), Cheiracanthiidae (3), Mimetidae (3) and Pholcidae (1) (Fig. 2).

In horticultural ecosystem, a total of 1010 Nos. individuals of spider was collected and comprises with 13 Nos. of families under 41 Nos. of genus and 65 Nos. of species. The maximum diversity at generic level was found in the family Araneidae (8) followed by Ganophosidae (7), Salticidae (6), Lycosidae (4), Tetragnathidae (3), Theridiidae (3), Zodariidae (3), Thomisidae (2), Oxyopidae (1), Clubionidae (1), Cheiracanthiidae (1), Corinnidae (1) and Linyphiidae (1) (Plate 2). On the other hand maximum individuals were found in family Araneidae (402) followed by Tetragnathidae (141), Lycosidae (113), Salticidae (108), Ganophosidae (85), Theridiidae (44), Linyphiidae (40), Zodariidae (21), Thomisidae (18), Oxyopidae (18), Corinnidae (12), Cheiracanthiidae (5) and Clubionidae (3) (Fig. 3).

At maize ecosystems a total of 615 Nos. individuals of Archinids were collected which composed with 5 numbers of families under 15 Nos. of genus and 29 Nos. of species. Maximum species was collected at the month of July to august. The maximum diversity of araneofauna found in generic level in family Araneidae (7) followed by Tetragnathidae (4), Salticidae (2), Oxyopidae (1), Linyphiidae (1) and Lycosidae (1) (Plate 3). On the other hand maximum individuals were found in family Araneidae (439) followed by Tetragnathidae (103), Salticidae (40), and Linyphiidae (24), Lycosidae (9) and Oxyopidae (5) (Fig. 4).

In potato ecosystem, a total of 103 Nos. individuals of Arachnids was collected which comprised with 5 Nos. of families under 10 Nos. of genus and 12 Nos. of species (Plate 4). The maximum diversity at generic level was found in the family Ganophosidae (3) followed by Salticidae (3), Zodariidae (2), Cheiracanthiidae (1) and Lycosidae (1). Maximum species was collected at the month of December to February. On the other hand maximum individuals were found in family Salticidae (35) followed by Ganophosidae (32), Lycosidae (19), and Zodariidae (14) and Cheiracanthiidae (3) (Fig. 5).

At rice ecosystems a total of 567 Nos. individuals of Arachnids was collected and comprises with 10 Nos. of families under 27 Nos. of genus and 40 Nos. of species. The maximum diversity at generic level was found in the family Araneidae (8) followed by Ganophosidae (3), Salticidae (3), Tetragnathidae (3), Theridiidae (2), Lycosidae (2), Thomisidae (2), Mimetidae (1), Clubionidae (1), Oxyopidae (1) and Uloboridae (1) (Plate 5). On the other hand maximum individuals were found in family Araneidae (273) followed by Lycosidae (111), Oxyopidae (77), Tetragnathidae (76), Salticidae (33), Ganophosidae (21), Theridiidae (21), Clubionidae (11), Thomisidae (10), Mimetidae (5) and Uloboridae (7) (Fig. 6).

\subsubsection{Insecta}

The present study was restricted to collection of major arthropods from 5 ecosystems Viz., silvicultural, horticultural, potato, maize and rice ecosystems. A total of 727 Nos. of samples collected belongings in the group Pterygota (Table 2). Among Pterygotes orders like Orthoptera, Dermeptera, Hemiptera, Odonata, Dictyoptera, Isoptera, Ephimeroptera and Phasmatodea were observed which belonged to division Exopterygota and orders like Coleoptera, Neuroptera, Diptera, Lepidoptera and Hymenoptera were belonged to the division Endopterygota. In the class insecta maximum familial diversity was found in silvicultural ecosystem followed by horticultural, rice and maize ecosystems. The maximum diversity was found in the order of Hemiptera (22 Nos. of families), the majority of individuals fall under the family Aphididae (50), Pyrrhocoridae (12), Nepidae (9), Pseudococcidae (8) and Coreidae (8) etc. The aquatic hemipteran was represented by the 2 families Nepidae (genus Ranatra and Lethocerus) and Belostomatidae (genus Belostoma). 


\subsection{Species richness indices}

\subsubsection{Alpha diversity}

\subsubsection{In observed ecosystems}

In observed ecosystems Shannon Wiener index was found maximum at species level in silvicultural ecosystem (3.409) followed by horticultural (3.332), rice (2.644), potato (2.193) and maize (2.091) ecosystem (Table 4). In whole sampling period the Shannon Wiener index in species level was ranged in silvicultural (2.250-3.9362), horticultural (2.547-3.341), maize (2.918-3.158), potato (1.672-2.614) and rice (630-2.891) ecosystems . Likewise the other beta diversity indices such as Species number, Margelef D, Equitability J etc. were calculated and represented in the Fig. 7.

\subsubsection{In Individual ecosystems}

\subsection{Berger parker index}

The maximum ordinal value was observed in November (0.803) and minimum in December $(0.541)$ in silvicultural ecosystem. In the horticultural system maximum at ordinal level was observed in September (0.965) and minimum in December (0.797). . In maize, potato and rice ecosystems the maximum Berger parker index was observed in August (0.930), February (0.727) and September (0.855) while minimum in July (0.838), September (0.571) and July (0.745) respectively. Similarly the values of Berger parker index at familial and species level were calculated and represented in the Fig. 8 .

\subsection{Species number}

The species number was calculated based on ordinal level during the period from July, 2019 to February, 2020. In silvicultural ecosystem, araneofauna was found to be maximum in month of September (14) and minimum found in the month of February (4). Similarly under horticultural system the maximum number in araneofauna found in the months of August and October (5) and minimum in the month of February (3). In maize, potato and rice ecosystem, 4 Nos. of species was found to be maximum in the month of September while 2 Nos. of species was observed to be minimum in August, November and August respectively in maize, potato and rice ecosystem. Similarly the values of species number at familial and species level were calculated and represented in the Fig. 9.

Likewise other values of Alpha diversity indices such as Shannon wiener index Simpsons D, Species number, Margelef D, Equitability J, Berger Parker index, Maclntosch U, Brillouin level, Fisher Alpha and Q Statistic were calculated and represented in the Fig. 10. The indices were calculated month wise for each ecosystem at species, familial and Ordinal level from $27^{\text {th }}$ SMW of July, 2018 onwards till $06^{\text {th }}$ SMW of February, 2019 (Table 5).

\subsubsection{Beta diversity indices at species, familial and ordinal level}

In the current study of beta diversity indices, Whittaker Bw, Cody Bc, Routledge Br, Routledge Bi, Routledge Be and Wilson \& Shmida Bt were used to compare the species composition of Arachnids communities in all the five ecosystems Viz. silvicultural, horticultural, maize, potato and rice ecosystem. Analysis based on Whittaker $\mathrm{Bw}$ at species level revealed that variation was highest in silvicultural ecosystem (1.170) followed by horticultural (1.000), rice (0.487), potato (0.343) and maize (0.128) ecosystem. Cody Bc index was found maximum in silvicultural ecosystem (77.500) followed by Horticulture (42.000), rice (11.000), maize (4.500) and potato (1.500) ecosystem. The trend of variation of beta indices at falilial and ordinal level is represented in the table 6 . 


\section{Discussion}

At silvicultural ecosystems a total of 1001 Nos. individuals of Arachnids were collected which composed with 18 numbers of families under 58 Nos. of genus and 99 Nos. of species. Maximum species was collected at the month of July to august. The maximum diversity of araneofauna found in generic level in family Araneidae (13) followed by Salticidae (9), Tetragnathidae (7), Ganophosidae (5), Theridiidae (4), Lycosidae (4), Zodariidae (3), Sparassidae (2), Thomisidae (2), Philodromidae (1), Pholcidae (1), Linyphiidae (1), Oxyopidae (1), Mimetidae (1), Clubionidae(1), Corinnidae (1), Cheiracanthiidae (1) and Pisauridae (1). The results were found similar to the respective works by Chetia and Kalita (2012), Quasin (2011), Bhattacharya et al. (2017), Otto and Floren (2007) who also reported maximum diversity in Orb weavers followed by Ambushers and Hunters in forest canopy. Chetia and Kalita (2012) reported maximum diversity in family Araneidae followed by Salticidae, Tetraganthidae from Gibbon wild life century, Assam. Quasin (2011) reported Araneidae as the dominant family (18\%) followed by Salticidae and Thomisidae (11.5\%), Theridiidae (8.6\%), Linyphiidae (7.4\%), Uloboridae and Tetragnathidae (4.5\%) in Nanda Devi Biosphere Reserve, Dehradun. Bhattacharya et al. (2017) reported maximum diversity of areal spiders as family Araenidae followed by Tetraganthidae and Thomisidae from different habitats at Jaintia hills of Meghalaya. Chetry and Moran (2019) reported araneofauna from Arunachal Pradesh, the maximum diversity was found in family Araneidae followed by Salticidae and Tetraganthidae.

In horticultural ecosystem, a total of 1010 Nos. individuals of silvicolous spider was collected which comprised of 13 Nos. of families under 40 Nos. of genus and 65 Nos. of species. The maximum diversity at generic level was found in the family Araneidae (8) followed by Ganophosidae (7), Salticidae (6), Lycosidae (4), Tetragnathidae (3), Theridiidae (3), Zodariidae (3), Thomisidae (2), Oxyopidae (1), Clubionidae (1), Cheiracanthiidae (1), Corinnidae (1) and Linyphiidae (1). Similar results with our study were also reported by Brown et al. (2003) who observed dominant families were Araneidae, Tetragnathidae, Lycosidae, Salticidae, Ganophosidae, Theridiidae in horticultural ecosystems. Deshmukh and Chaudhari (2016) reported maximum diversity of spider families were Araneidae, Salticidae and Lycosidae in citrus ecosystems. Sankari and Thiyagesan (2010) and Bhat et al. (2013) also found the maximum diversity in families Araneidae followed by Tetraganthidae and Lycosidae in horticultural ecosystem. Tahir et al. (2015) found most dominant family in citrus ecosystem was Lycosidae followed by Salticidae, Araneidae and Linyphiidae while the present study revealed the dominant family was Araneidae followed by Lycosidae, Salticidae and Lynphillidae. In case of ground dwelling spider's maximum diversity was found in the families' Lycosidae followed by Ganophosidae and Salticidae which are also agreement with the results of Tahir et al. (2011). In winter season maximum diversity was found in the families' Clubionidae and Corrinnidae similar results also found by Divina and Jorge (1999) in lime orchard. Stenchly et al. (2011), Kacar (2015) and Asarkar and Ade (2017) also found same results in horticultural ecosystems. On the other hand the one third of the collection period belonged in monsoon season and the study area experiencing heavy rainfall because of heavy rainfall the effectiveness of pitfall traps were reduced.

At maize ecosystems a total of 615 Nos. individuals of Archinids were collected which composed of 5 numbers of families under 15 Nos. of genus and 29 Nos. of species. The maximum diversity of araneofauna was found in generic level in family Araneidae (7) followed by Tetragnathidae (4), Salticidae (2), Linyphiidae (1), Oxyopidae (1) and Lycosidae (1). On the other hand maximum individuals were found in family Araneidae (439) followed by Tetragnathidae (103), Salticidae (40), Linyphiidae (24), Lycosidae (9) and Oxyopidae (5). Similar results were reported from field crop ecosystems by Khan and Rather (2012), Joseph and Premila (2016) and Rajendran et al. 
(2017) who reported maximum diversity in families Araneidae followed by Tetraganthidae and Salticidae in field crop ecosystems. Rajeswaran et al. (2017) reported the families Oxyopidae and Lycosidae from maize ecosystem. Saranya et al. (2019) reported the dominated families Salticidae, Lycosidae and Oxyopidae and the genera Pardosa, Lycosa and Hippasa from maize ecosystem. The present study repoeted maximum diversity in orb weavers (Araneidae and Tetraganthidae) which may be attributed to the robust growth and development of maize crop i.e. the web spiders were observed to highly correlate with size and complexity of crop canopy and not prey availability, Greenstone (1984).

In potato ecosystem, a total of 103 Nos. individuals of Arachnids was collected with comprises of 5 Nos. of families under 10 Nos. of genus and 12 Nos. of species. The maximum diversity at generic level was found in the family Ganophosidae (3) followed by Salticidae (3), Zodariidae (2), Cheiracanthiidae (1) and Lycosidae (1). Similar results were reported from Solanaceous crop ecosystems by Sankari and Thiyagesan (2010) who reported the dominated ground dwelling spider family was Lycosidae in egg-plant ecosystem. Murali et al. (2017) reported the dominant families were Salticidae, Lycosidae, Oxyopidae, Araneidae and Cheiracanthiidae in brinjal ecosystem. Khan (2013) reported hunting and running spiders from temperate vegetable ecosystems from Kashmir. The present report maximum diversity found in ground dwelling spiders because of poor canopy development of potato crop due to prolonged dry spell and the abundance of areal spiders are positively correlated with complexity of canopy, Greenstone (1984).

At rice ecosystems a total of 567 Nos. individuals of Arachnids was collected comprising of with 10 Nos. of families under 24 Nos. of genus and 40 Nos. of species. The maximum diversity at generic level was found in the family Araneidae (8) followed by Ganophosidae (3), Salticidae (3), Tetragnathidae (3), Theridiidae (2), Lycosidae (2), Thomisidae (2), Mimetidae (1), Clubionidae (1), Oxyopidae (1) and Uloboridae (1). Similar results were reported from rice ecosystems by Thakur et al. (1995) who were reported the araneofauna of rice ecosystem was dominated by families Arancidae, Tetragnathidae, Salticidae, Lycosidae, Oxyopidae and Clubionidae. Prabal and Mayuri (2008) observed the spider fauna of Sali and Boro rice from Lakhimpur, Assam, and observed the dominated species were Oxyopes and Tetragnatha in selected seed bed, main field and ratoon crop. Jayakumar and Sankari (2010) found a total of 5 genera Viz., Lycosa, Callitrichia, Tetragnatha, Argiope and Plexippus were found to be common among 6 different sowing techniques of rice crop. Joseph and Premila (2016) also found maximum diversity in families Arancidae, Tetragnathidae and Salticidae in rice ecosystem.

\subsection{Alpha diversity}

Deshmukh and Chaudhari (2016) reported Shannon diversity index and Evenness to be 1.98 and 0.9 respectively in Orange farm. Rajini (2016) reported the highest species diversity in banana ecosystem (3.55) followed by paddy field (3.23) and the lowest was observed in lady's finger ecosystem (2.30). In the case of Simpson index, the maximum value was 0.90 in banana ecosystem and the minimum was 0.55 in lady's finger field The species richness of spiders was greater in banana ecosystem (2.51) followed by paddy field (1.94). The evenness value was maximum in lady's finger ecosystem (0.87) followed by groundnut ecosystem (0.82). Zaki et al. (2015) found Shannon-Wiener Index and Simpson Index in between 0.76-1.48, 0.24-0.67 respectively in tomato ecosystem. Rendon et al. (2006) evaluated the biodiversity of 2 systems of coffee plantation and found ranges of Species richness (6-51), Shannon index (1.16-2.94), Simpson index (0.101-0.455). Bhat et al. (2013) found Shannon index (4.20), Simpson index (0.04), Evenness index (0.50), Margale D (14.73) in cashew system. Riaza et al. (2017) found the ranges of species richness (37-42), Eveness (0.71-0.88) and Shannon Wiener index (3.311-3.405) in sunflower and soybean field crop ecosystems. Stokmane and Spungis (2016) found the range of Shannon index to be 0.50 to 2.25 for ground-dwelling 
spiders and 0.14 to 1.86 for grass-dwelling spiders. Species evenness was 0.87 for the ground-dwelling spiders and 0.68 for the grass-dwelling spiders in calcareous fen ecosystem. Bhattacharya et al. (2017) found Shannon Wiener index (2.17) and Evenness index (0.7) in different ecosystem plotted in forest, shrub habitats and five numbers of houses from Meghalaya. Deshmukh and Raut (2014) found Shannon index 1.06, Simpson index 0.10, Margalef Richness Index 8.42 from different ecosystems. Bhuvad et al. (2011) recorded Simpson's index to be highest in mango (0.119) followed by rice (0.103), finger millet (0.081), cashew (0.054) and the values of Shannon diversity index was 3.41, 3.02, 2.81 and 2.73 in cashew, mango, finger millet and rice respectively. Goswami et al. (2015) found that Shannon diversity varied from 1.73-2.17, while Simpson index was between 0.13-0.18, Margelef richness index was found to be between 1.15-1.86, while Evenness index ranged between 0.69-0.72 at different growth stages of rice crop. Saranya et al. (2019) found the species number (5-16), Fisher's Alpha (1.941-5.705), Margalef D (1.4673.067), Brillouin index (0.992-2.514), Shannon Weiner (H') index (1.427-2.594), Q statistic (2.327- 13.915), Simpson index (4.683-5.142), Equitability J (0.514- 0.9493) in different growth stages of maize crop. 


\section{Reference:}

Anitha G and Vijay J 2016, Quantification of the abundance and diversity of predatory spiders in rice ecosystem of Rajendranagar, Telangana, India, J. Appl. Nat. Sci., 8(2), 1010-14

Asarkar GM and Ade PP 2017, Spider Density \& Diversity in Agroecosystem of Akola district (Vidharbh). India. Int. J. Life Sci., A8, 103-8

Barrion AT and Litsinger JA 1995 Riceland spiders of south and southeast Asia (UK: CABI)

Batten LA 1976, Bird communities of some Killarney woodlands. http://www.jstor.org/stable/20519019, Pp. 285-313, May 6, 1976.

Berger WH and Parker FL 1970, Diversity of planktonic foraminifera in deep-sea sediments, Sci., 168, 1345-47

Bhat PS, Srikumar KK and Raviprasad TN 2013, Seasonal Diversity and Status of Spiders (Arachnida: Araneae) in Cashew Ecosystem, World Appl. Sci. J., 22(6), 763-70

Bhattacharya A, Chetri M and Sarkar P 2017, Spider diversity in different habitats at Jaintia Hills of Meghalaya, Int. J. Life. Sci., 5(4), 613-19

Bhuvad NV, Patil VK, Bhave SG, Narkhede SS, Jalgaonkar VN and Mhaiske VM 2011, Spider diversity attributes in a cultural landscape dominated by field crops and fruit orchards in the konkan region of Maharashtra, ENVIS Bulletin: Arthropods and their Conservation in India (Insects \& Spiders), 14(1), 21-33

Bogya S (1999) Spiders (Araneae) as polyphagous natural enemies in orchards, Ph. D. Thesis, Agricultural University of Wageningen, Netherland.

Bouseksou S, Kherbouche-Abrous O and Beladjal L 2015, Ecology of Araneae (Arthro poda, Arachnida) populations in two agroecosystems: wheat and oilseed rape in the Mitidja plain (Algeria), Life Environ., 65(4), 257-64

Brown MW, Schmitt JJ and Abraham JB 2003, Seasonal and diurnal dynamics of spiders (Araneae) in West Virginia Orchards and the effect of Orchard Management on Spider Communities, Environ. Entomol., 32(4), 830-39

Chetia P and Kalita DK 2012, Diversity and distribution of spiders from Gibbon Wildlife Sanctuary, Assam, India, Indian J. Arachnol., 1(1), 130-42

Clifford HT and Stephenson W 1975 An introduction to numerical classification (London: Academic Press)

DeLong JrDC 1996, Defining biodiversity, Wildl. Soc. Bull., 24(4), 738-49

Deshmukh US and Chaudhari PW 2016, Study of spider fauna from orange agro ecosystem in the catchment area of upper Wardha dam, Amravati, Maharashtra, India, Int. J. Fauna Biol. Stud., 3(5), 120-23

Deshmukh US and Raut NM 2014, Seasonal Diversity and Status of Spiders (Arachnida: Araneae) in Salbardi forest (Satpura Range), Maharashtra, India, J. Entomol. Zool. Stud., 2(6), 278-81

Divina MA and Jorge EP 1999, Predatory spider in Lime orchards and their importance in control of Citrus leafminer, Phyllocnistis citrella (Lepidoptera: Gracillaridae), Proc. Fla. State Hort. Soc., 112, 222-24

Fisher RA 1940, The precision of discriminant functions, Ann. Eugn., 10, 422-29

Goswami TN, Kiran K and Kole B 2015, Quantitative estimation of spider fauna in rice ecosystem of Zone IIIA in Bihar, Environ. Ecol., 33(2), 783-85

Greenstone MH 1984, Determinants of web spider species diversity: vegetation structural diversity vs. prey availability, Oecolog., 62, 299-304

Jayakumar S and Sankari A 2010, Spider population and their predatory efficiency in different rice establishment techniques in Aduthurai, Tamil Nadu, J. Biopestic., 3(1), 20-27

Joseph AR and Premila KS 2016, A study on the richness of spider fauna in rice ecosystem, J. Entomol. Zool. Stud., $4(2), 425-30$ 
Kacar G 2015, Biodiversity of Spider Species, Interactions with Horticultural Crops and a New Record for Turkey, Pakistan J. Zool., 47(2), 545-50

Kempton RA and Taylor LR 1976, Models and statistics for species diversity, Nat., 262, 818-20

Khan AA 2009, Biodiversity of spider fauna (Arachnida: Araneae) in horticultural ecosystem of Kashmir, J. Biol. Control., 25(2), 103-13

Khan AA 2013 Spider fauna (Arachnida: Araneae) of temperate vegetable ecosystem of Kashmir; in Biotechnological approaches in crop protection (eds) Prasad D and Ray DP (New-Delhi: Biotech books) pp 400-14

Khan AA and Khan ZH 2011 Spider fauna (Arachnida: Araneae) in horticultural ecosystem; in Animal Diversity, Natural History and Conservation (eds) Gupta VK (New Delhi: Daya Publishing House) pp 313-38.

Khan AA and Rather AQ 2012, Diversity and foraging behaviour of spider (Arachnida: Araneae) in the temperate Maize ecosystem of Kashmir, J. Biol. Control., 26(2), 179-89

Kujur R and Ekka A 2016, Inventorization of Spider fauna of IndraVihar Park, Raigarh, Chhattisgarh, India, J. Environ. Sci. Toxicol. Food Technol., 1(2), 20-26

Magurran AE 2004 Measuring Biological diversity (UK: Blackwell Science Ltd)

McIntosh RP 1967, An index of diversity and the relation of certain concepts to diversity, Ecol., 48(3), 392-404

Murali S, Jalali SK, Shylesha AN, Swamy STM and Gracy GR 2017, Predatory spider fauna in Brinjal crop their abundance and composition, J. Entomol. and Zool. Stud., 5(5), 675-81

Otto S and Floren A 2007, The spider fauna (Araneae) of tree canopies in the Białowieża Forest, Fragm. Faun., 50(1), $57-60$

Platnick NI 2011, The world spider catalog, version 12.0. American Museum of Natural History, https://research.amnh.org/iz/spiders/catalog_12.0/index.html.

Prabal S and Mayuri B 2008, Spider fauna of rice ecosystem in Northern Assam. J. Appl. Zool. Res., 19(2), 163-66

Quasin S 2011, Diversity of Spiders in Nanda Devi Biosphere Reserve. Project Report Department of Science and Technology (SERC), New Delhi, DST No. SR/SO/AS-66/2005, pp. 36-158

Rajendran R, Kaliyaperumal S and Periyasamy K 2017, Diversity and Distribution of Spider(Araneae) in Different Ecosystem of Puthanampatti, Tiruchirappalli District, Tamil Nadu, South India, Int. J. Sci. Eng. Res., 8(10), $1056-60$

Rajeswaran J, Duraimurugan P and Shanmugam PS 2005, Role of spiders in agriculture and horticulture ecosystem, $J$. Food, Agric. Environ., 3(3\&4), 147-52

Ranjini S 2016, Preliminary studies on the spider fauna in selected agro-ecosystems of Kozhinjampara Panchayat, Palakkad district, Kerala, Int. J. Recent Sci. Res., 7(10), 13740-43

Rendon MAP, Ibarra-Nunez G, Parra-Tabla V, Garcia-Ballinas JA and Henaut Y 2006, Spider diversity in Coffee plantations with different management in Southeast Mexico, J. Arachnol., 34, 104-12

Riaza S, Kausara S, Mohsinb M, Memonb AM, Maqsoode I and Abbasa MN 2017, Spider Diversity in Some Common Oilseed Crops in Central Punjab, Pakistan, Pakistan J. sci. Ind. Res., 60(3), 168-75

Routledge RD 1977, On Whittaker's components of diversity, Ecol., 58(5), 1120-27

Sankari A and Thiyagesan K 2010, Population and predatory potency of spiders in brinjal and snakegourd, $J$. biopestic., 3(1), 28-32

Sankari A and Thiyagesan K 2010, Population and Predatory Potency of Web-building Spiders in Tapioca (Manihot utilissima) Crop-fields, Res. J. Biol. Sci., 3-9 
Saranya VSL, Samiayyan K and Prema MS 2019, Diversity of predatory spider fauna in maize ecosystem, J. Biol. Control., 33(1), 27-35

Schuldt A, Fahrenholz N, Brauns M, Migge-Kleian S, Platner C and Schaefer M 2008, Communities of ground-living spiders in deciduous forests: Does tree species diversity matter?, Biodivers. Conserv., 17, 1267-84

Simpson EH 1949, Measurement of diversity, Nat., 163, 688

Stenchly K, Clough Y, Damayanti BD and Tscharntke T 2011, Spider web guilds in cacao agroforestry-comparing tree, plot and landscape-scale management, Divers. Distrib., 17, 748-56

Stokmane M and Spungis V 2016, The influence of vegetation structure on spider species richness, diversity and community organization in the Apsuciems calcareous fen, Latvia, Anim. Biodivers. Conserv., 39(2), 221-36

Swingland IR 2001 Biodiversity, definition of; in Encyclopedia of biodiversity (eds) Levin SA (California: Academic Press) pp 377-91

Tahir HM, Butt A, Naheed R, Bilal M and Alam I 2011, Activity Density of Spiders Inhabiting the Citrus Field in Lahore, Pakistan, Pakistan J. Zool., 43(4), 683-88

Tahir HM, Nazarat I, Naseem S, Butt A, Yaqoob R, Mukhtar MK and Samiullah K 2015, Seasonal Dynamics of Spiders and insect Pests in Citrus Orchards of District Sargodha, Pakistan, Pakistan J. Zool., 47(6), 1673-81

Thakur JN, Singh JP, Verma OP and Diwakar MC 1995, Spider fauna in the rice ecosystem of Jammu, J. Biol. Control., 9(2), 125-26

Tikader BK 1987 Hand book of Indian spiders (Calcutta: The director, zoological survey of India)

Tikader BK and Bal A 1980, Studies on spiders of the genus Zygeilla Cambridge from India (Araneae: Araneidae). Proceedings of the Indian Academy of Science (Anim. Sci.), Pp.243-246, May 1980, Bangaluru, India

Wilson MV and Schmida A 1984, Measuring beta diversity with presence-absence data, J. Ecol., 72(3), 1055-64

Zaki AY, Aly AI, Eid RA and Mergawy MM 2015, Biodiversity of Ground Spiders (Araneae) Occurred in Tomato and Tomato Yield Fertilized with Different Organic Manures in Fayoum Governorate, Egypt. Acad. J. Biolog. Sci., 8(3), 87-96 




- Silvicultural ecosystem

- Horticultural ecosystem

Rice ecosystem

Maize ecosystem

- Potato ecosystem

Figure 1

Arachnids in familial level in observed ecosystem 




Figure 2

Total numbers (\%) of individuals in familial level in Silvicultural ecosystem 


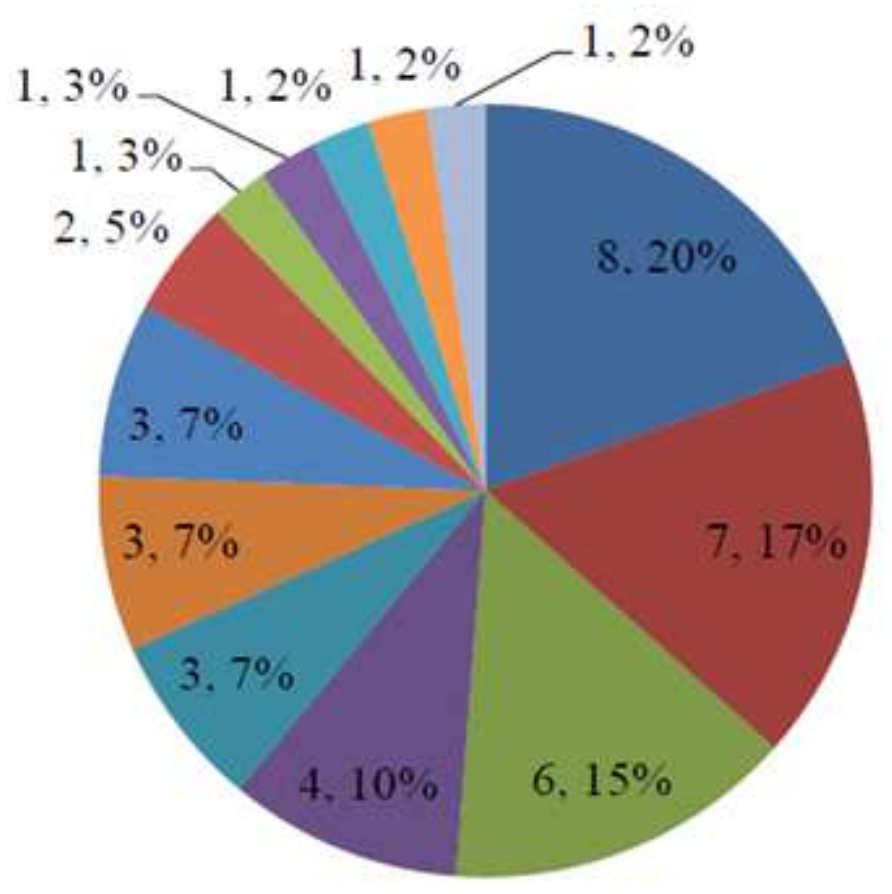

- Araneidae

manophosidae

- Salticidae

- Lycosidae

n Tetragnathidae

= Theridiidae

m Zodariidae

- Thomisidae

- Linyphiidae

=xyopidae

m Corinnidae

= Cheiracanthiidae

- Clubionidae

\section{Figure 3}

Total Number of Arachnid genera found in Horticultural ecosystem

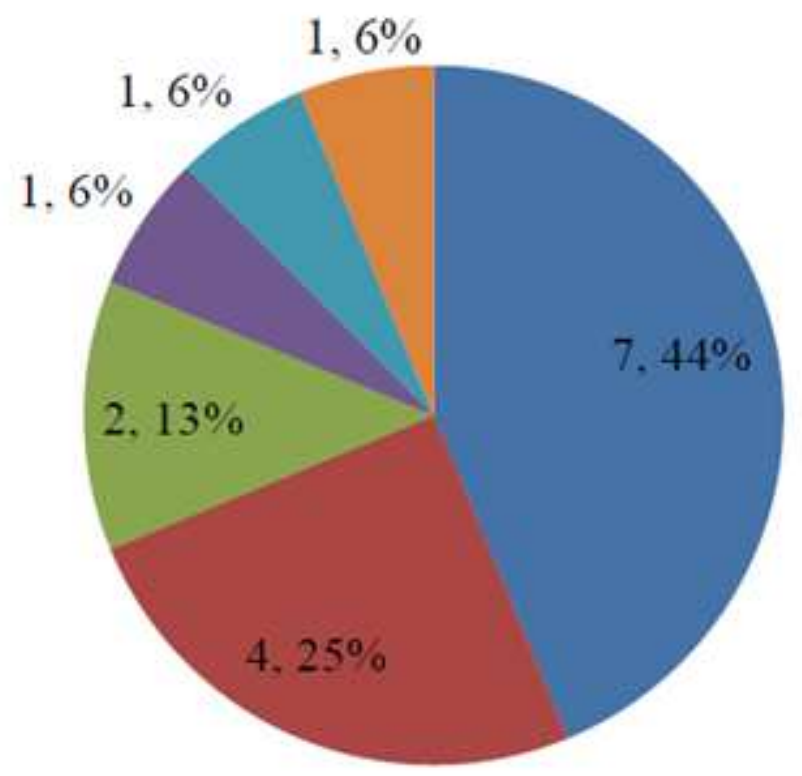

- Araneidae

- Tetragnathidae

Salticidae

- Linyphiidae

aycosidae

- Oxyopidae

\section{Figure 4}

Total Number of Arachnid genera found in Maize ecosystem 


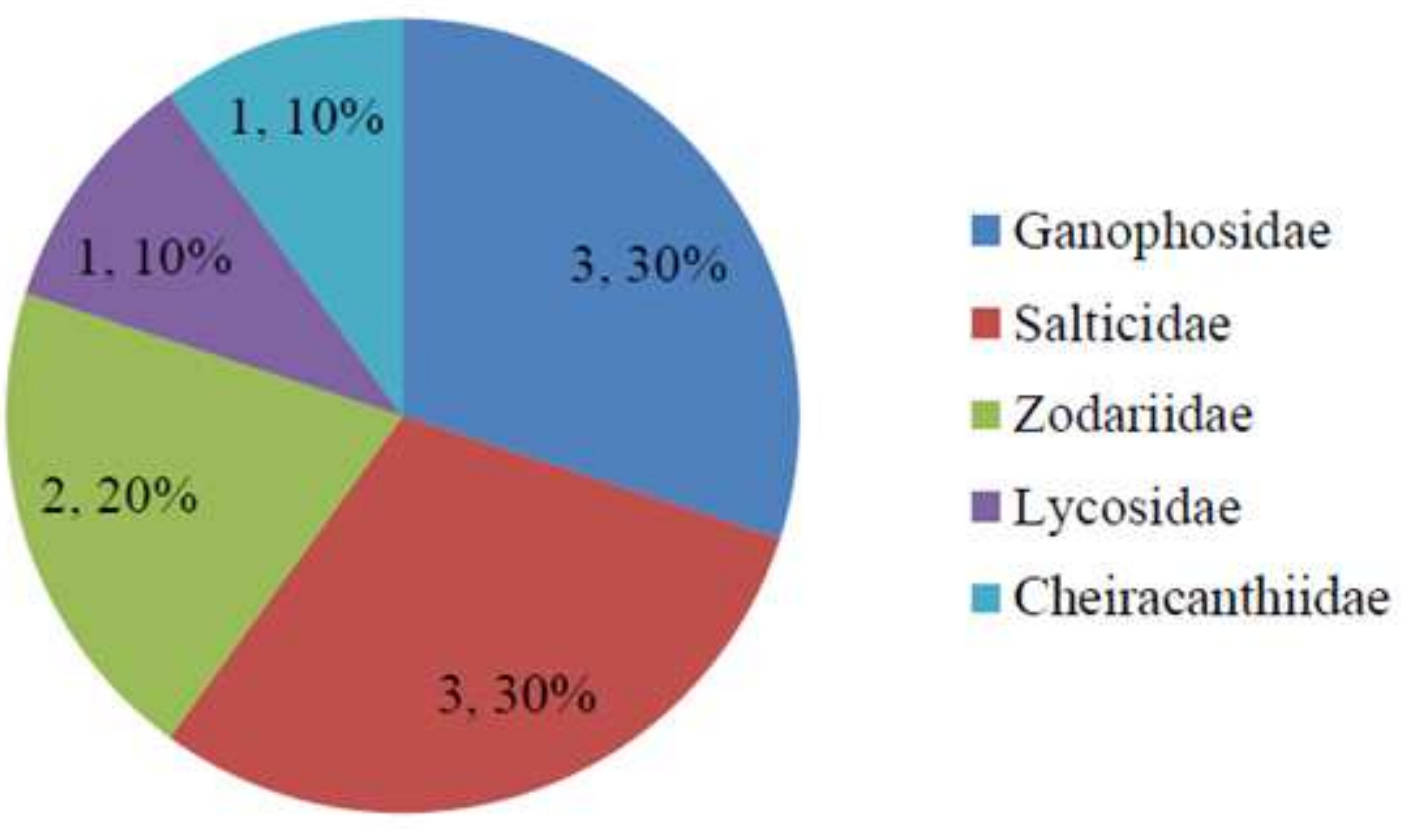

Figure 5

Total Number of Arachnid genera found in Potato ecosystem



Araneidae

- Ganophosidae

- Salticidae

- Tetragnathidae

- Lycosidae

a Theridiidae

= Thomisidae

- Mimetidae

- Uloboridae

Oxyopidae

Clubionidae

Figure 6

Total Number of Arachnid genera found in Rice ecosystem 


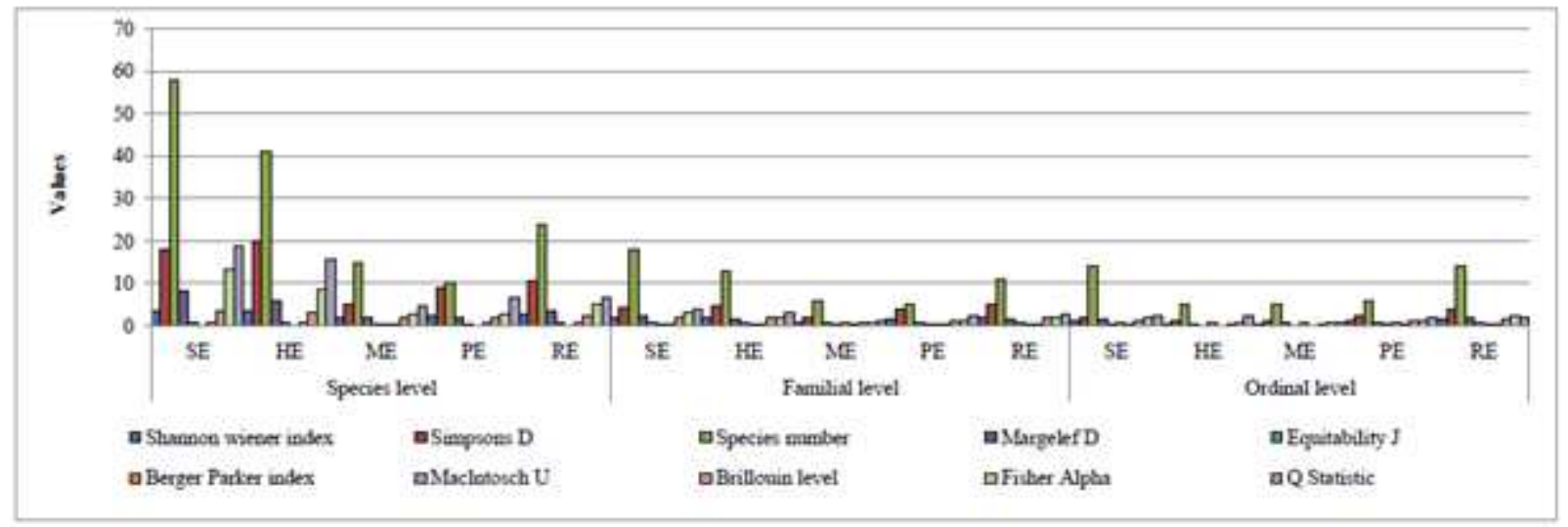

Figure 7

Overall Arthropod diversity in terms of total individuals in observed ecosystems

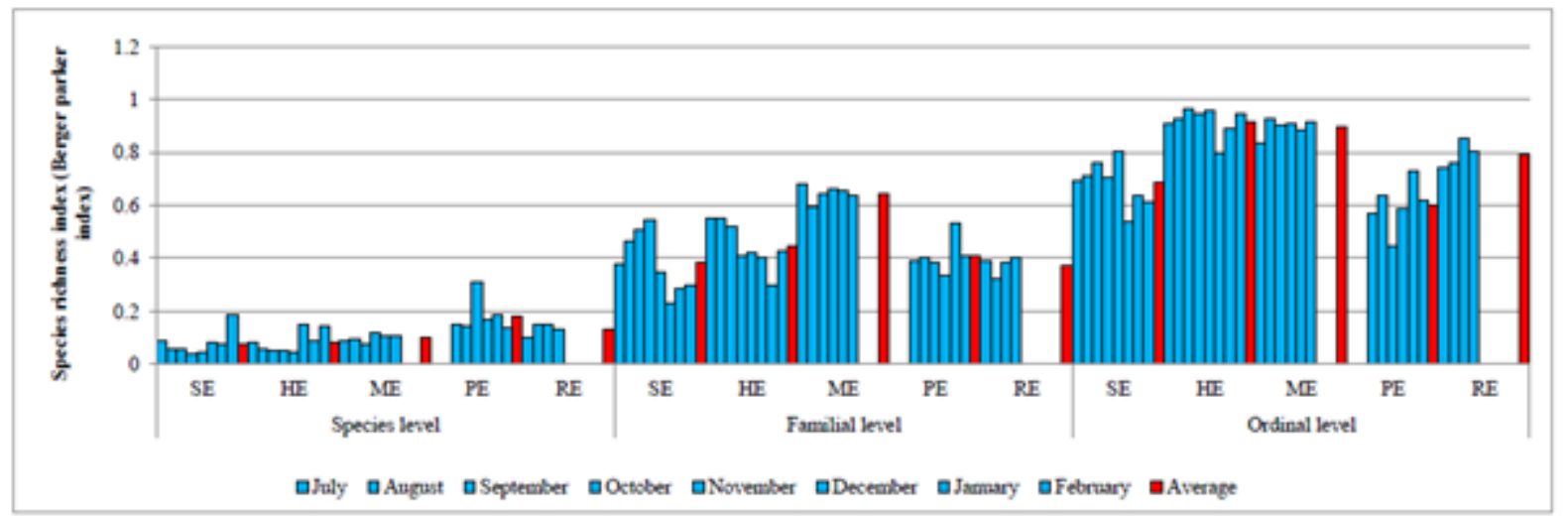

\section{Figure 8}

Berger parker index from 27th SMW of July, 2019 onwards till 06th SMW of February, 2020 in observed ecosystems

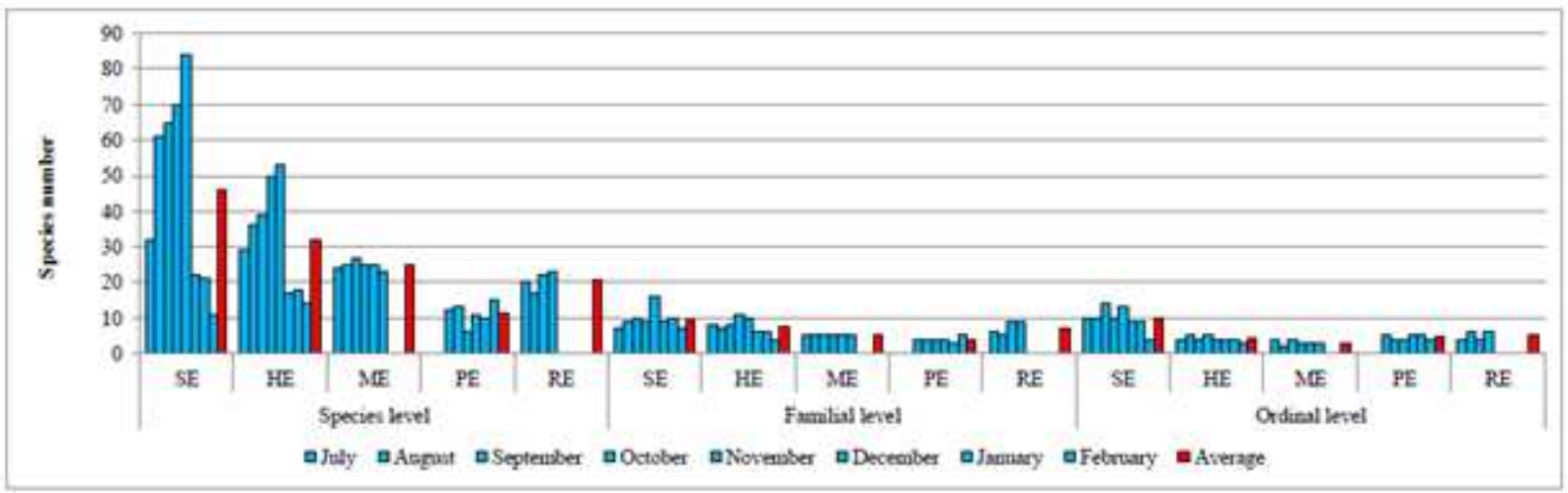

\section{Figure 9}

Values of Species number from 27th SMW of July, 2019 onwards till 06th SMW of February, 2020 in observed ecosystems 


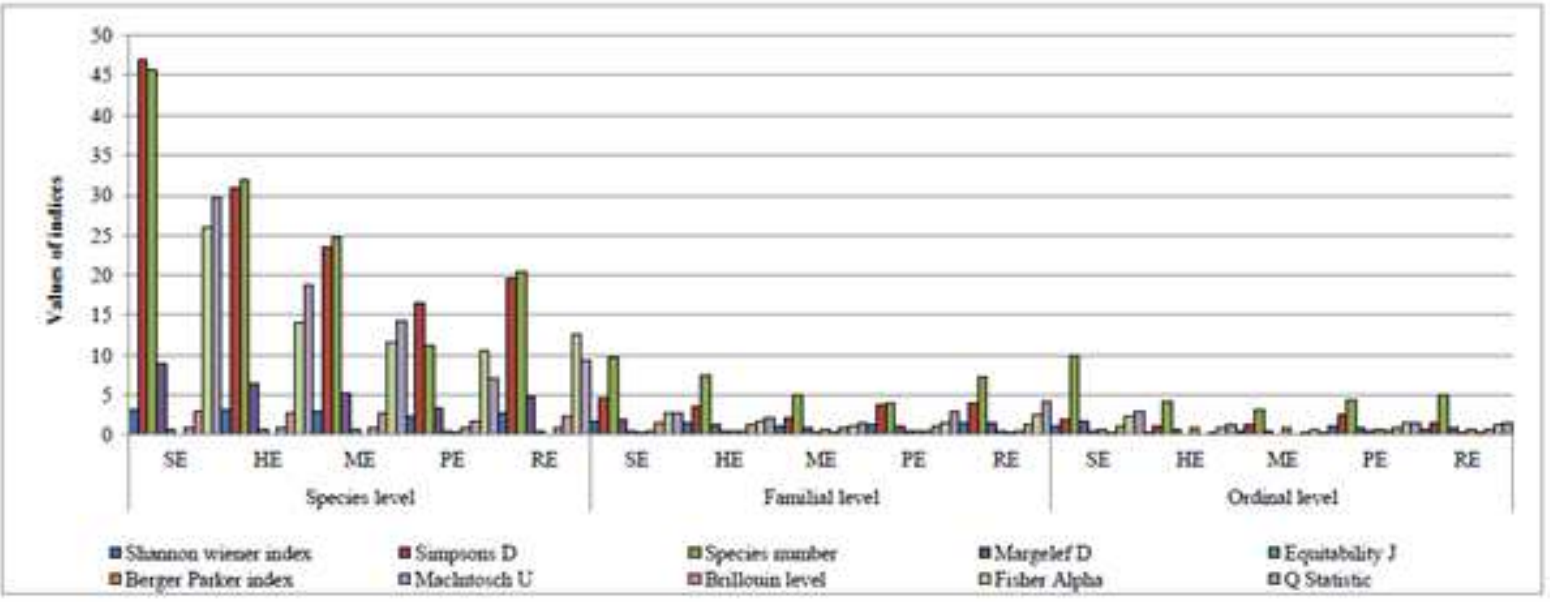

Figure 10

Summarised values of Alpha diversity from 27th SMW of July, 2019 onwards till 06th SMW of February, 2020 in observed ecosystems

\section{Supplementary Files}

This is a list of supplementary files associated with this preprint. Click to download.

- Table.pdf

- Plates15.pdf 